\title{
Students' Attitudes and Approaches towards Physics Problem Solving: Basis for Intervention Program
}

\author{
Reymond L. Mallari \\ Department of Education, Schools Division of Pampanga, Sta. Maria High School, Philippines \\ reymond.mallari@ deped.gov.ph
}

DOI: 10.29322/IJSRP.10.11.2020.p10728

http://dx.doi.org/10.29322/IJSRP.10.11.2020.p10728

\begin{abstract}
Learning problem-solving abilities is among the most vital issues of physics curriculum, although it is the zone where learners get the most difficulties. It is considered a challenging matter for students in the secondary to tertiary level of education. Assessing students' attitudes and solutions to address Physics problems is important in determining which strategies must be used by teachers to handle these situations and in encouraging students to find a more interesting point of view of physics and not to stress or feel worried as they have learned the principle of physics. This study assessed and measured the attitudes and approaches towards Physics Problem Solving of the 50 twelfth grade students. A descriptive research design using an adopted survey questionnaire was used in the study. The results of the study revealed that the attitude and approaches of the learners in Physics Problem Solving were generally described as; somewhat aware on the process of problem solving and take control on the process that leads them to enjoyment $(\mathrm{M}=3.83)$; utilize sometimes pictures, illustrations, or scratch works in solving physics problems $(\mathrm{M}=3.79)$; somewhat perceive approaches in solving problems $(\mathrm{M}=3.85)$; classified themselves as "novices" as they immediately substitute formula into numbers rather than understand first the given problems $(\mathrm{M}=3.83)$; understand the application of the problem-solving process in real world set-up $(\mathrm{M}=3.81)$; and they are confident enough and sometimes feel sophisticated in solving problems in physics $(M=3.74)$. This evaluative study will be used in planning and devising the appropriate teaching strategy to implement inclined to students' different approaches.
\end{abstract}

\section{Keywords: students' attitudes and approaches, physics problem solving}

\section{Introduction}

Physics is well thought out to be the most difficult discipline in the field of science and traditionally fascinates a limited percentage of students relative to other branches of science. It is regarded as a complicated subject for learners from secondary to higher education. This is partly due to the learning processes involved in studying physics, which enable learners to deal with various types of diagrams, such as formulas, equations, diagrams, depictions, and also conceptual comprehension at the existential level (Saleh, 2014). In addition, learners are engaged in a pact to solve problems. Teaching problem solving is one of the most serious matters of teaching physics, and it is also the area where students have the most difficulties.

The 2002 Basic Education Curriculum postulates that the purpose of science education is to enable every Filipino learner to gain a practical scientific literacy linked to real-life circumstances, to achieve the scientific knowledge, values and attitudes needed to analyze and solve daily social problems. When attempting to solve the problems of physics, students always say that they understand the issues, they understand the facts of physics upon which issue is centered, they have solved several similar problems, but the new problem is different from the previous ones, so they cannot solve the problem.

Educational policies today strive to improve individuals with 21 st century skills perceived to be universal necessity and problemsolving skills is one of the skills that emerged as a prerequisite of the 21 st century. However, at the same time, the prevailing issue in schools is that students have a bad attitude, which makes the learning process severe. In order to address this issue, it is necessary to explore the attitude of students towards teaching physics not only in senior high school but also in junior high school.

Enabling successful learning for students is the main goal of education that is affected by few factors, such as the attitude of students towards learning and the characteristics of the learning environment (Al-Qahtani, 2012). Extensive research has shown that a person's behaviors are learned rather than inherited, including past experiences and social factors. Many factors can affect a person's attitude, including past experiences and social influences. Cracker (2006) described an attitude towards science as a positive or unfavorable feeling about science as a school subject.

The influence of students ' attitudes and approaches to solving Physics problems is critical in deciding which techniques must be implemented by the teacher to deal with this situation and in helping students to find a more interesting topic of physics and not to fear or worry as they have studied the concept of physics. A pessimistic attitude towards the subject leads to a lack of interest in attending and engaging in any activity related to the subject. Thus, a positive attitude towards science, however, leads to a positive interest to science that affects sustained interest to learn in science (Ricardo, 2006).

Teachers play a crucial role in the lives of students in their classrooms. Beyond that an educator has many other responsibilities, such as mentoring and nurturing students, creating a healthy classroom atmosphere, being a role model and, most importantly, 
setting students' moods to inspire them to be involved and value learning. Research demonstrates that the effectiveness of the instructor has an effect on the academic success of his or her students. It is crucial that teachers trust with themselves and their competence as positive examples and teachers, since they have a critical part to play in the self-perception and success of their students. A positive attitude towards teaching and learning to solve problems in physics is then a key to increase students' incentive to follow healthy learning habits. In addition, students will need to make efforts and refine their negative attitudes.

Physics educational research has described behaviors and values of students as leading to higher academic achievement (Mistades, 2011). The attitude of learners to one subject or another has been shown to lead to good performance in this subject. A negative attitude towards a certain subject makes learning challenging, while a positive attitude allows students to make efforts and contributes to a high level of achievement in the subject (Veloo, et. al, 2015). Godwin and Okoronka (2015) have shown that there is a important relationship between the attitude of students and their subsequent academic success in physics. Measuring the attitude of students to the subject is therefore a valuable activity if one wants to enhance the performance of students in the subject.

With these in mind, the researchers performed a report that had a meaningful effect on the education system. The current study filled the knowledge gap and reacted to the behaviors and approaches of senior high school students to the Physics Problem Solving program and will serve as a framework for action or creativity. In this context, the results of the surveys identified the issues to be addressed and whether there are changes and innovations that will allow learners to achieve successful quality education.

The research was based on cognitive learning theory. In which the person learns through thought. It can be explained by observing the individual's mental processes. The use of the Attitudes and Approaches in Problem Solving Survey (APPS) questionnaire was considered to be the input of the research, while the conduct of the survey was considered to be the method and the formulation of the intervention / innovation program based on the findings was the output of the research.

The figure below shows the Paradigm of the study.
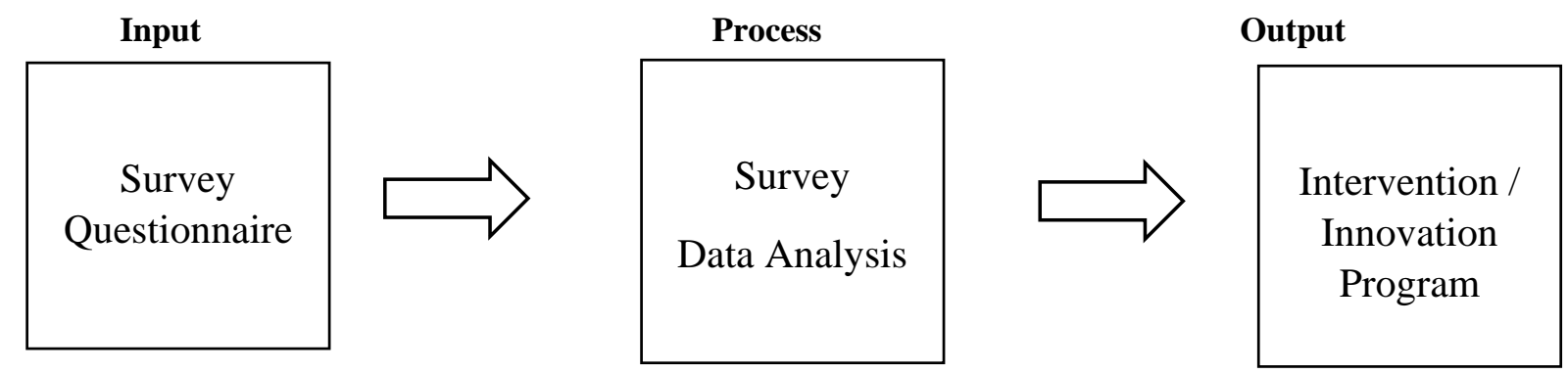

In this study, it sought to determine and assess Senior High School Students' Attitudes and Approaches towards Physics Problem Solving. Specifically, the research questions address in this study are as follows:

1. How do Senior High School Students' Attitudes and Approaches towards Physics Problem Solving be described in terms of;
1.1. Metacognition and enjoyment
1.2. Utility of pictures, diagrams or scratch work
1.3. Perception of problem-solving approach
1.4. General expert-novice differences
1.5. Sense-making
1.6. Problem solving confidence and sophistication

2. Based on the results, what may be suggested?

\section{Methods}

A quantitative approach has been adopted in this research as it is a systematic method of identifying and evaluating the attitudes and approaches of senior high school students to the Physics Problem Solving method, using the numerical and analytical data obtained from the respondents ' responses to the questionnaires.

The researchers used a descriptive research design to create a detailed analysis. This type of research design identified the current conditions and other relevant details of the topic in the analysis. By definition, Salaria (2012) defined the descriptive method as an analytical process of collecting, evaluating, classifying and tabulating data on prevailing circumstances, behaviors, attitudes, procedures, patterns, and then providing an appropriate and accurate analysis of the data collected.

The sample of this study consisted of 50 Twelfth Grade Students on the academic and technical-vocational and subsistence paths of Grade 12 of Sta. Maria High School. Respondents of the research were selected randomly using a stratified random sampling. Below is a table that shows the percentages of the respondents. 
Table 1 shows the Distribution of the Respondents.

\begin{tabular}{|c|c|c|}
\hline Strata/Section & Population & Sample \\
\hline Genesis & 8 & 2 \\
\hline Exodus & 29 & 9 \\
\hline Leviticus & 30 & 10 \\
\hline Numbers & 30 & 10 \\
\hline Deuteronomy & 30 & 10 \\
\hline Joshua & 27 & 9 \\
\hline Total & 154 & 50 \\
\hline
\end{tabular}

This research adopted the survey questionnaire entitled, Attitudes and Approaches in Problem Solving (AAPS). It consists of 31 statements explaining various facets / factors for solving physical problems such as: metacognition and enjoyment, use of photographs, diagrams or scratches, understanding of problem-solving approach, general expert-novel discrepancies, sensemaking, and problem-solving trust and complexity. Using the 5-point related scale, the respondents were directed by how they would agree / disagree on the corresponding statements in the survey form.

The data collected in this study was treated and analyzed using the Microsoft Excel and Stata 11 Software Program which is a statistical software designed for easy tabulation. In analyzing the collected data, appropriate statistical treatment was used; Arithmetic Mean, to find out the average of a set of numerical values, computed by adding them together and dividing by the number of terms and to determine the senior high school students' attitudes and approaches in solving problems in Physics.

\section{Results and Discussion}

This study focused on determining the senior high school students' attitudes and approaches towards physics problem solving in terms of the 6 facets/factors (metacognition and enjoyment, utility of pictures, diagrams or scratch work, perception of problemsolving approach, general expert-novice differences, sense-making, and problem-solving confidence and sophistication). The findings of the study were presented in tables together with verbal descriptions and interpretations.

\section{Metacognition and Enjoyment in Problem Solving}

Metacognition implies that critical thinkers become mindful of their own problem-solving process, take charge of this process, and seek assistance whenever necessary. Metacognition questions talk about what students do as they solve problems and their level of satisfaction and trust when they solve problems.

It is evident on the table below that senior high school students' metacognition and enjoyment on problem solving is generally weighted with 3.83 which indicates that students are somewhat aware on the process of problem solving and take control on process which leads them to enjoyment.

\begin{tabular}{|c|l|c|}
\hline No. & \multicolumn{1}{|c|}{ STATEMENTS } & $\begin{array}{c}\text { Arithmetic } \\
\text { Mean }\end{array}$ \\
\hline 4 & $\begin{array}{l}\text { In solving problems in physics, I always identify the physics principles } \\
\text { involved in the problem first before looking for corresponding equations. }\end{array}$ & $\mathbf{3 . 9 6}$ \\
\hline 6 & $\begin{array}{l}\text { In solving problems in physics, I can often tell when my work and/or answer } \\
\text { is wrong, even without looking at the answer in the back of the book or } \\
\text { talking to someone else about it. }\end{array}$ & $\mathbf{3 . 3 2}$ \\
\hline 7 & $\begin{array}{l}\text { To be able to use an equation to solve a problem (particularly in a problem } \\
\text { that I haven't seen before), I think about what each term in the equation } \\
\text { represents and how it matches the problem situation. }\end{array}$ & $\mathbf{3 . 6 4}$ \\
\hline 10 & $\begin{array}{l}\text { If I am not sure about the correct approach to solving a problem, I will reflect } \\
\text { upon physics principles that may apply and see if they yield a reasonable } \\
\text { solution. }\end{array}$ & $\begin{array}{l}\text { If I used two different approaches to solve a physics problem and they gave } \\
\text { different answers, I would spend considerable time thinking about which } \\
\text { approach is more reasonable. }\end{array}$ \\
\hline 14 & $\begin{array}{l}\text { When I solve physics problems, I always explicitly think about the concepts } \\
\text { that underlie the problem. }\end{array}$ & $\mathbf{3 . 9 6}$ \\
\hline 20 & $\begin{array}{l}\text { After I solve each physics homework problem, I take the time to reflect and } \\
\text { learn from the problem solution. }\end{array}$ & $\mathbf{3 . 9 8}$ \\
\hline 21 & $\begin{array}{l}\text { After I have solved several physics problems in which the same principle is } \\
\text { applied in different contexts, I should be able to apply the same principle in }\end{array}$ & $\mathbf{3 . 8 8}$ \\
\hline
\end{tabular}




\begin{tabular}{|c|l|c|}
\hline 22 & other situations. & $\mathbf{3 . 8 4}$ \\
& $\begin{array}{l}\text { If I obtain an answer to a physics problem that does not seem reasonable, I } \\
\text { spend considerable time thinking about what may be wrong with the problem } \\
\text { solution. }\end{array}$ & $\mathbf{3 . 8 4}$ \\
\hline 25 & $\begin{array}{l}\text { When I do not get a question correct on a test or homework, I always make } \\
\text { sure learn from my mistakes and do not make the same mistakes again. }\end{array}$ & $\mathbf{4 . 0 4}$ \\
\hline 27 & I enjoy solving physics problems even though it can be challenging at times. \\
\hline 29 & $\begin{array}{l}\text { If I realize that my answer to a physics problem is not reasonable, I trace back } \\
\text { my solution to see where I went wrong. }\end{array}$ & $\mathbf{3 . 9 6}$ \\
\hline & General Weighted Mean & $\mathbf{3 . 8 3}$ \\
\hline
\end{tabular}

The research published by Netto and Valente in 1997 cited by Ince (2018) looked at the effects of students using cognitive knowledge techniques to overcome their physical problems. In this semi-experimental research, the problem-solving abilities of secondary school students were examined using problem-solving interventions, including cognitive awareness strategies. The results of the study indicated that students who applied cognitive awareness techniques to problem-solving behavior were better at problem-solving.

Taasoobshirazi and Ferley 's research published in 2013 looked at the relationship between the motives of professional problem solvers, the ability to use metacognition methods, the ability to categorize problems, and the ability to use free body diagrams to solve physical problems. According to the findings of the analysis, clarified by the structural equation model, the motivation variable strategy affects metacognitive preparation and problem categorization, and the strategy of competence and problem categorization increases the ability to solve problems.

\section{Utility of pictures, diagrams or scratch work in Physics problem solving}

It is apparent on the table below that senior high school students' utilization of illustrations in solving problem is generally weighted with 3.79 which indicates that students sometimes use pictures, diagrams, and scratch work whenever they solve problems in Physics.

\begin{tabular}{|c|l|c|}
\hline No. & \multicolumn{1}{|c|}{ STATEMENTS } & Arithmetic Mean \\
\hline 15 & $\begin{array}{l}\text { When solving physics problems, I often find it useful to first draw a picture or } \\
\text { a diagram of the situations described in the problems. }\end{array}$ & $\mathbf{3 . 7 8}$ \\
\hline 17 & $\begin{array}{l}\text { I am equally likely to draw pictures and/or diagrams when answering a } \\
\text { multiple-choice question or a corresponding free-response (essay) question. }\end{array}$ & $\mathbf{3 . 7 2}$ \\
\hline 18 & $\begin{array}{l}\text { I usually draw pictures and/or diagrams even if there is no partial credit for } \\
\text { drawing them. }\end{array}$ & $\mathbf{3 . 8 2}$ \\
\hline 19 & $\begin{array}{l}\text { I am equally likely to do scratch work when answering a multiple-choice } \\
\text { question or a corresponding free-response (essay) question. }\end{array}$ & $\mathbf{3 . 7 9}$ \\
\hline
\end{tabular}

In 2001, Zou discussed the effect of using graphics in the field of work-energy on the problem-solving skills of students. In a study conducted with 3 Physical Problem Solutions and Interviews, he stated that with the use of graphics, students could better understand the principles on which the problem was based, create equations more specifically, and better assess the solution of the problem. In addition, Kohl and Finkelstein (2005) studied the impact of statistical, pictorial, visual and descriptive presentations on students' problem-solving skills in the field of physics. In this work, which was carried out semi-experimentally with homework, including these 4 dimensions, which are mathematical, pictorial, graphic and expressive, it has been reported that students can solve the problems indicated by visual gestures more easily.

On the other hand, Yiğit et al. (2012) examined the capacity of science students to read the problems in physics classes and to deliver correct results on paper. The research, using a screening model, was conducted with 40 students. To this end, 5 openended questions were used and the responses were categorized according to the student's ability to turn texts into shapes and describe shape-based texts. The results of the study showed that the students were unable to understand what was mentioned and what was asked in the questions posed in text and type.

\section{Perception of problem-solving approach}


The table below shows that senior high school students' perception of problem-solving approach is generally weighted with 3.85 which specifies that students somewhat perceive approach as a component or part of the problem-solving process.

\begin{tabular}{|c|l|c|}
\hline No. & \multicolumn{1}{|c|}{ STATEMENTS } & Arithmetic Mean \\
\hline 5 & $\begin{array}{l}\text { "Problem solving" in physics basically means matching problems with the } \\
\text { correct equations and then substituting values to get a number. }\end{array}$ & $\mathbf{4 . 2}$ \\
\hline 8 & There is usually only one correct way to solve a given problem in physics. & $\mathbf{3 . 7}$ \\
\hline 9 & $\begin{array}{l}\text { I use a similar approach to solving all problems involving momentum even if } \\
\text { the physical situations given in the problems are very different. }\end{array}$ & $\mathbf{3 . 8 6}$ \\
\hline 11 & $\begin{array}{l}\text { Equations are not things that one needs to understand in an intuitive sense; I } \\
\text { routinely use equations to calculate numerical answers even if they are non- } \\
\text { intuitive. }\end{array}$ & $\begin{array}{l}\mathbf{3 . 8 6} \\
\text { shysics involves many equations each of which applies primarily to a specific }\end{array}$ \\
\hline 26 & $\begin{array}{l}\text { It is more useful for me to solve a few difficult problems using a systematic } \\
\text { approach and learn from them rather than solving many similar easy problems } \\
\text { one after another. }\end{array}$ & $\mathbf{3 . 8 8}$ \\
\hline & & General Weighted Mean \\
\hline
\end{tabular}

Özcan's study released in 2011 examined at the problem-solving methods of pre-service physics teachers to address the problems of special relativity theory. In this study with 34 university students, two problems and semi-structured interview questions were used to define problem-solving methods for students. The findings of the study showed that the problem-solving activity of most pre-service teachers was not scientific or did not provide an effective strategic approach.

In 2012, Abubakar and Danjuma discussed the effect of an explicit problem-solving approach (focusing on the problem, identifying the problem, preparing for a solution, executing the plan, and assessing the solution) on academic achievement and remembrance of students. The Solomon quartet was used in this research, which they performed with 80 high school students. The physics efficiency test developed by the researchers themselves was used as a means of measurement. Based on the results of the three-dimensional study of variance, this approach is the best approach to boost the academic performance of students in high school physics classes and to enable them to recall past experience.

\section{General expert-novice differences in physics problem solving}

It is reflected on the table below that senior high school students' expert-novice differences in physics problem solving is generally weighted with 3.83 which explains that students are somewhat be classified as "novices" since they simply attempt to plug or substitute numbers into formula rather than first try to understand the problems.

\begin{tabular}{|c|l|c|}
\hline No. & \multicolumn{1}{|c|}{ STATEMENTS } & Arithmetic Mean \\
\hline 8 & There is usually only one correct way to solve a given problem in physics. & $\mathbf{3 . 7}$ \\
\hline 21 & $\begin{array}{l}\text { After I have solved several physics problems in which the same principle is } \\
\text { applied in different contexts, I should be able to apply the same principle in } \\
\text { other situations. }\end{array}$ & $\mathbf{3 . 8 8}$ \\
\hline 24 & $\begin{array}{l}\text { When I have difficulty solving a physics homework problem, I like to think } \\
\text { through the problem with a peer. }\end{array}$ & $\mathbf{3 . 8 6}$ \\
\hline 28 & I try different approaches if one approach does not work. & $\mathbf{3 . 9 6}$ \\
\hline 29 & $\begin{array}{l}\text { If I realize that my answer to a physics problem is not reasonable, I trace back } \\
\text { my solution to see where I went wrong. }\end{array}$ & $\mathbf{3 . 8 3}$ \\
\hline
\end{tabular}

Dhillon (1997) examined variations in the problem-solving behavior of expert and inexperienced problem solvers. The research included 1 teaching staff at the Faculty of Physics, 2 Physics Department PhD students, 4 Physics Department Graduate Students, 6 First Grade Physics University Students. 14 of the participants were asked to think loud when solving the problems of physics. The written test was used, and the whole process was documented in the report. As per the results of the analysis, the main objective of the inexperienced problem solvers was to solve the problem, while the experienced problem solvers sought to imagine the problem and use the problem-solving techniques.

Heller et al. (2001) examined the beliefs of teaching staff and students in the Physical Departments of Universities on teaching and learning topics. The data obtained through the interviews revealed that the teaching staff felt that some students assumed that problem solving was a linear process, but that problem solving involved self-monitoring and assessment during the process. 


\section{Sense-making in physics problem solving}

It is evident on the table below that senior high school students' sense-making on problem solving is generally weighted with 3.81 which indicates that students are somewhat aware on the application of the problem solving in Physics in the real-world scenario.

\begin{tabular}{|c|l|c|}
\hline No. & \multicolumn{1}{|c|}{ STATEMENTS } & Arithmetic Mean \\
\hline 2 & $\begin{array}{l}\text { When solving physics problems, I often make approximations about the } \\
\text { physical world. }\end{array}$ & $\mathbf{3 . 6 4}$ \\
\hline 5 & $\begin{array}{l}\text { "Problem solving" in physics basically means matching problems with the } \\
\text { correct equations and then substituting values to get a number. }\end{array}$ & $\mathbf{3 . 6}$ \\
\hline 16 & $\begin{array}{l}\text { When answering conceptual physics questions, I mostly use my "gut" feeling } \\
\text { rather than using the physics principles I usually think about when solving } \\
\text { quantitative problems. }\end{array}$ & $\mathbf{3 . 8 1}$ \\
\hline
\end{tabular}

\section{Problem solving confidence and sophistication}

The table below shows that senior high school students' confidence and sophistication on problem solving is generally weighted with 3.74 which indicates that students are somewhat confident and sophisticated in solving physics problems.

\begin{tabular}{|c|l|c|}
\hline No. & \multicolumn{1}{|c|}{ STATEMENTS } & Arithmetic Mean \\
\hline 1 & $\begin{array}{l}\text { If I'm not sure about the right way to start a problem, I'm stuck unless I go see } \\
\text { the teacher/TA or someone else for help. }\end{array}$ & $\mathbf{3 . 8 8}$ \\
\hline 3 & $\begin{array}{l}\text { In solving problems in physics, being able to handle the mathematics is the } \\
\text { most important part of the process. }\end{array}$ & $\mathbf{3 . 9 6}$ \\
\hline 6 & $\begin{array}{l}\text { In solving problems in physics, I can often tell when my work and/or answer } \\
\text { is wrong, even without looking at the answer in the back of the book or } \\
\text { talking to someone else about it. }\end{array}$ & $\mathbf{3 . 6}$ \\
\hline 9 & $\begin{array}{l}\text { I use a similar approach to solving all problems involving momentum even if } \\
\text { the physical situations given in the problems are very different. }\end{array}$ & $\mathbf{3 . 9 8}$ \\
\hline 20 & $\begin{array}{l}\text { After I solve each physics homework problem, I take the time to reflect and } \\
\text { learn from the problem solution. }\end{array}$ & $\mathbf{3 . 4 6}$ \\
\hline 23 & If I cannot solve a physics problem in 10 minutes, I give up on that problem. \\
\hline 24 & $\begin{array}{l}\text { When I have difficulty solving a physics homework problem, I like to think } \\
\text { through the problem with a peer. }\end{array}$ & $\mathbf{3 . 8 4}$ \\
\hline 25 & $\begin{array}{l}\text { When I do not get a question correct on a test or homework, I always make } \\
\text { sure learn from my mistakes and do not make the same mistakes again. }\end{array}$ & $\mathbf{3 . 8 4}$ \\
\hline & \multicolumn{1}{|c|}{ General Weighted Mean } \\
\hline
\end{tabular}

Byu and Lee (2014) examined whether students' self-confidence, academic performance and intellectual comprehension varied with an increase in the amount of physical problems resolved. In a study conducted with 49 high school students, the Force Definition Test and Physical Course Performance Grades were used as evaluating instruments and interviews were conducted with 4 selected students. Students have solved an average of 2200 physics problems. The implications of this study showed that the increase in the amount of physics problems solved had little effect on students' academic performance, self-confidence and comprehension of concepts, and that students' ability to solve physical problems could be improved by the techniques learned and applied.

\section{Conclusion}

Based on the results of the study, the following conclusions were drawn;

1. As reflected on the responses of the students on Attitude and Approaches in Problem Solving, it generally describes that students;

1.1. Are somewhat aware on the process of problem solving and take control on the process that leads them to enjoyment.

1.2. Utilize sometimes pictures, illustrations, or scratch works in solving physics problems.

1.3. Perceive approaches in solving problems

1.4. Are classified as "novices" as they immediately substitute formula into numbers rather than understand first the given problems.

1.5. Understand the application of the problem-solving process in real world set-up. 
1.6. Are confident enough and sometimes feel sophisticated in solving problems in physics.

\section{Recommendations}

1. The researchers recommend that teachers of Physics should assess students' strength and weaknesses in problem solving in physics. This assessment will be used to plan and to implement the appropriate teaching strategy and teach students different approaches.

2. The researchers suggest to the future researchers to study the correlation between the Attitudes and Approaches in solving problems to the Academic Performance of the students.

\section{References}

Abubakar, S. M., \& Danjuma, I. M. (2012). Effects of Explicit Problem-Solving Strategy on Students`Achievement and Retention Senior Secondary School Physics. Journal of Science, Technology \& Education, 1(1), 123-128.

Al-Qahtani, M. (2016). Measuring healthcare students' attitudes toward interprofessional education. Journal of Taibah University Medical Sciences. 11. 10.1016/j.jtumed.2016.09.003.

Byu, T., \& Lee, G. (2014). Why Students Still Can’t Solve Physics Problems after Solving over 2000 Problems. American Journal of Physics, 82, 906-913. https://doi.org/10.1119/1.4881606

Cracker, D. (2006). "Attitudes towards science of Students enrolled in Introductory Level Science Courses". UW-L Journal of Undergraduate Research IX, 1-6.

Dhillon, A. S. (1998). Individual Differences within Problem-Solving Strategies used in Physics. Science Education, 82(3), 279405. https://doi.org/10.1002/(SICI)1098-237X(199806)82:3<379::AID-SCE5>3.0.CO;2-9

Godwin, B.A., and Okoronka, U.A (2015). Attitude and Academic Performance of senior Secondary School Students in Physics in Nigeria.

Heller, P., Heller, K., Henderson, C. R., Kuo, V., \& Yerushalmi, E. (2001). Instructors' Beliefs and Values about Learning Problem Solving. Part of the PER Conference Series, July 25-26, Rochester, New York. https://doi.org/10.1119/perc.2001.pr.005

Ince, E. (2018). An Overview of Problem Solving Studies in Physics Education. Journal of Education and Learning; Vol. 7, No. 4; 2018. Published by Canadian Center of Science and Education. https://doi.org/10.5539/jel.v7n4p191

Özcan, Ö. (2011). Pre-service physics teachers' problem-solving approaches in special theory. Hacettepe University Journal of Education, 40, 310-320.

Salaria, Neeru. (2012). Meaning of the Term- Descriptive Survey Research Method. International Journal of Transformations in Business Management. (IJTBM) 2012, Vol. No. 1, Issue No. 6.

Saleh, Salmiza. (2014). Malaysian students' motivation towards Physics learning. European Journal of Science and Mathematics Education.

Taasoobshirazi, G. \& Farley, J. (2013). Construct Validation of the Physics Metacognition Inventory. International Journal of Science Education. 35. 447-459. 10.1080/09500693.2012.750433.

Trumper, R. (2006). Factors Affecting Junior High School Students' Interest in Physics. Journal of Science Education and Technology. 15. 47-58. 10.1007/s10956-006-0355-6.

Van Heuvelen, A. \& Zou, X. (2001). Multiple representations of work-energy processes. American Journal of Physics, 69(2), 184.

Veloo, A., Nor, R. and Khalid, R. (2015). Attitudes towards Physics and additional Mathematics Achievement towards Physics Achievement.,8(3),35-43. International Education Studies,8(3),35-43

Yiğit, N. \& Alev, N., (2011, September). Physics student teachers' technological pedagogical content knowledge (TPCK): Using video to promote reflection on practice. Paper presented at the European Conference on Educational Research, Berlin, Germany. 